\title{
Ice velocities of the Lambert Glacier from static GPS observations
}

\author{
Rachael Manson ${ }^{1}$, Richard Coleman $^{1,2}$, Peter Morgan $^{3}$, and Matt King ${ }^{1}$ \\ ${ }^{1}$ Centre for Spatial Information Science, University of Tasmania, GPO Box 252-76, Hobart, Tasmania 7001, Australia \\ ${ }^{2}$ CSIRO Marine Research, GPO Box 1538, Hobart, Tasmania 7001, Australia \\ ${ }^{3}$ School of Computing, University of Canberra, PO Box 1, Belconnen, Australian Capital Territory 2616, Australia
}

(Received December 25, 1999; Revised June 21, 2000; Accepted June 29, 2000)

\begin{abstract}
Between 1988 and 1995, five seasons of Global Positioning System (GPS) data were collected at seventy-three locations near the 2500 metre contour of the Lambert Glacier Drainage Basin (LGB). These data have been processed using GAMIT/GlobK software to determine surface velocities at the surveyed sites. Results show that velocities along the traverse route vary between $0.5 \mathrm{ma}^{-1}$ and $63 \mathrm{ma}^{-1}$ with the location of the major outlet glaciers inside the LGB clearly identifiable within the data. A subset of the LGB GPS data has been studied to investigate an efficient method for determination of ice velocities at remote sites within a single field season. Results from this study have shown that ice velocities within $2 \%$ of the long-term estimate may be determined using two to four hour GPS site occupations separated in time by a minimum of forty days.
\end{abstract}

\section{Introduction}

The Antarctic ice-sheet stores the majority of the Earth's freshwater and therefore any changes in its volume will have an effect on global sea level (Meier, 1993). Critical areas to be monitored for change are the drainage basins and outlet glaciers, through which most of the continental ice is discharged to the coast.

The most significant drainage basin in East Antarctica is the Lambert Glacier Drainage Basin (LGB) (Fig. 1). The LGB covers more than one million square kilometres and drains $16 \%$ of the East Antarctic ice sheet (Phillips et al., 2000) through $1.7 \%$ of the coastline (Budd et al., 1967). This large system is one of the six major Antarctic drainage basins (Giovinetto and Bentley, 1985) and is therefore an important component in determining the state of balance of the entire Antarctic ice-sheet. The LGB has been the subject of mass balance studies by scientists since the 1960's and is currently thought to have a slightly positive mass imbalance (Phillips et al., 2000).

Mass-balance and other glaciological studies require knowledge of ice thickness, ice velocity, surface elevation and snow accumulation either from direct field measurements or via remote sensing methods. GPS has become a standard tool for field measurement of ice kinematics and surface topography in the interior of the Antarctic continent as it allows high precision measurements to be made relatively quickly and with minimum logistical support. Early work with GPS in Antarctica encountered problems due primarily to receiver instrumentation and ionospheric interference. Over the past decade, GPS hardware, software and satellite constellation have improved such that it is now reasonably simple to carry out remote ice movement surveys and produce high-quality results.

Copy right (C) The Society of Geomagnetism and Earth, Planetary and Space Sciences (SGEPSS); The Seismological Society of Japan; The Volcanological Society of Japan; The Geodetic Society of Japan; The Japanese Society for Planetary Sciences.
This paper presents the results of two studies using GPS data collected around the $2500 \mathrm{~m}$ elevation contour of the LGB between 1989 and 1995. Section 2 introduces the available GPS data and the following section describes the postprocessing of the data to determine ice-velocity. A summary of the LGB velocity results obtained from our data processing are presented in Section 4. Section 5 presents a case study in which we consider a more efficient GPS observation procedure for the collection of ice-sheet velocity data in remote areas.

\section{Survey Description}

Between 1989 and 1995 a set of five traverses approximately following the $2500 \mathrm{~m}$ surface contour of the ice sheet were undertaken in the Lambert Glacier Basin (Fig. 1). During the traverses, seventy-three marker poles were established at approximately $30 \mathrm{~km}$ intervals along the traverse route. Each of these poles was located by GPS on a minimum of two occasions during the LGB surveys to provide estimates of ice-velocity around the basin.

The early traverses, undertaken between 1989 and 1993, only occupied sites around the western perimeter of the basin. The GPS data collected during these surveys were of a consistently poor quality with very high noise levels and frequent L2 signal dropouts. Several factors contributed to degradation of this early data, the most significant being:

- Satellites: The constellation at the start of the survey period consisted of only ten satellites, increasing to twenty-one by the end of the 1992/93 survey. Also, at the latitudes of the survey region $\left(-67^{\circ}\right.$ to $\left.-76^{\circ}\right)$ the inclination of the orbital plane causes satellites to be observable only for short periods and at low elevation angles $\left(<70^{\circ}\right)$. The combination of these factors resulted in daily observation windows of three to four hours with only four to six available satellites. 


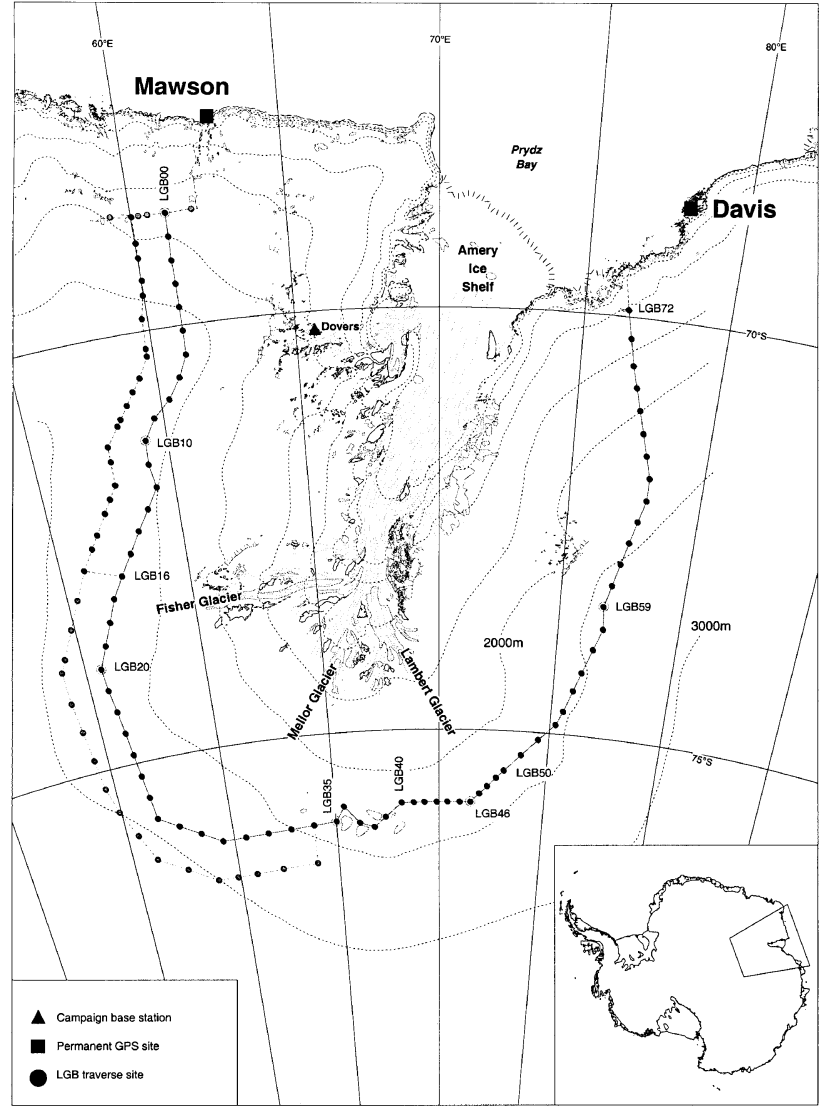

Fig. 1. The Lambert Glacier Basin, showing major glaciological features, fixed GPS sites and the LGB traverse routes.

- Ionosphere: The highly active nature of the Antarctic ionosphere at these latitudes has a significant effect on the quality of GPS data collected in the LGB region. At the time of the initial surveys, a peak in the 11year sunspot cycle (1990-91) caused the ionosphere to become even more volatile which amplified the effect on the GPS signals.

- Instrumentation: Wild Magnavox dual frequency instruments (WM102) were used to collect the GPS data. These receivers employed a multiplexing channel that was unable to maintain lock on the L2 signal at times of high ionospheric activity and therefore caused massive data dropouts on this frequency. In general, the useable data from these receivers consisted of short segments separated by large gaps and were affected by high noise levels.

- Reference Stations: The reference stations for the surveys were installed at fixed rock locations at or near the coast, up to $700 \mathrm{~km}$ from the traverse sites. WM102 receivers were used at the base stations and suffered levels of L2 data degradation similar to that experienced by the roving receivers. These two factors contributed to problems in obtaining satisfactory results during initial baseline processing of the data.
The LGB series of traverses were completed during the 1993/94 and 1994/95 Antarctic summer seasons. These final traverses were carried out using Leica299 dual frequency receivers and collected data from sites around the entire basin. Most of the problems encountered in the earlier traverses had been remedied by this time primarily due to improvements in receiver technology and satellite constellation as well as a decrease in ionospheric activity. Consequently, the data collected during this period were of a much higher quality and greater volume than the previous surveys.

\section{Data Processing}

During the period of the LGB traverses, proprietary software was used to process the GPS data in baseline solutions (Kiernan, in press). The velocities resulting from this initial processing were within the specifications for the survey ( $\pm 5 \%$; Craven et al., 1995) at most of the traverse sites. A comparative study carried out by Manson (1995) showed that higher precision results could be obtained from the LGB GPS data by using more sophisticated processing techniques.

In the study presented here, GAMIT software (King and Bock, 1999) has been used to process all of the GPS data from the LGB surveys. Separate processing strategies were required for the two survey periods, pre-1993 and post-1993, due to the differences in observing conditions and data quality experienced at these times.

The pre-1993 LGB surveys were processed in a global network using GPS data from all available sites. Permanent sites from CIGNET $^{1}$ (Chin, 1988) and the IGS $^{2}$ (Beutler and Kouba, 1998) formed the basis of our global network and additional sites from the SCAR' $91^{3}$ (Morgan and Tiesler, 1992) and GIG' $91^{4}$ (Melbourne et al., 1991) campaigns were used where possible to strengthen the network in the Southern Hemisphere. The final reference network used in the processing of the early LGB data consisted of between six and fifteen sites, mostly located in the Northern Hemisphere but with a sufficient number of southern latitude sites to provide a reasonable global coverage.

GAMIT's automatic data cleaning routines were used to flag or correct cycle slips and remove 'bad' data prior to the least squares solution of the double difference equations. A customised set of cleaning parameters was developed and tuned so that the worst of the LGB data would be automatically rejected whilst retaining sufficient epochs to determine a solution at each site. The major sections of the cleaning routines that required modification for our data processing were:

- more sensitive tolerances for cycle slip detection in the ionospheric delay.

- shorter epoch spans used in cycle slip repair, producing a better 'fit' to the data.

- tolerances set to remove a greater number of bias flags and preserve small segments of data.

In the cases where no site solution could be obtained after

\footnotetext{
${ }^{1}$ Cooperative International GPS Network.

${ }^{2}$ International GPS Service.

${ }^{3}$ Scientific Committee on Antarctic Research, GPS campaign, 1990/91.

${ }^{4}$ GPS IERS and Geodynamics Experiment, 1991.
} 
automatic data cleaning, sections of acceptable data were reactivated with interactive, manual editing and reweighting of the phase residuals. The cleaned data were then processed in a GAMIT least squares solution with full station coordinate and satellite orbit estimation using the ionosphere-free linear combination.

The enhanced quality of the GPS data, satellite orbits and reference network in the later seasons allowed standard GAMIT processing procedures and cleaning options (King and Bock, 1999) to be used. Some manual editing was required to remove cycle slips but this was minimal. A global network of up to 35 IGS sites was used in the processing of these data, again employing the ionosphere-free linear combination with full coordinate and orbit estimation.

The GAMIT solutions for each of the five survey seasons were then combined using GlobK/Glorg (Herring, 1999) software to produce position and velocity estimates. As a first step, the individual days from each season were combined into a seasonal estimate of position at each site. These seasonal estimates were then combined in a weighted multi-year GlobK/Glorg solution to determine the velocity parameters at each of the LGB sites with respect to the ITRF 1997 reference frame. This multi-year solution was performed backwards in time so that the strength of the network in 1994/95 was utilised in combining data from the earlier, weaker solutions.

\section{Velocity Results}

Horizontal velocities at each of the 73 sites along the LGB traverse were extracted from our multi-year GlobK solution (Fig. 2). Table 1 summarises the velocity results and their $2 \sigma$ standard deviations for all GPS sites on the LGB traverse. Surface slope and elevation in the region of the traverse were also determined but will not be presented here.

Maximum ice velocities were found, as expected, in the areas containing the major outlet glaciers and in coastal icesheet regions. Average velocities in the outlet glaciers are approximately $40 \mathrm{ma}^{-1}$, while velocities in the continental ice-sheet areas vary between $10 \mathrm{ma}^{-1}$ and $25 \mathrm{ma}^{-1}$.

The mean $(2 \sigma)$ precision of our velocity results is 0.108 $\mathrm{ma}^{-1}$ when considering all of the LGB data. However, due to the inconsistent nature of the data, it is more appropriate to look at the uncertainties of our results in two sub-sets; LGB(a) containing velocities observed during at least two campaigns from 1989/90 to 1994/95 and LGB(b) containing velocities obtained only from the 1993/94 and 1994/95 surveys. The mean velocity uncertainty for the LGB(a) sites is then found to be $0.221 \mathrm{ma}^{-1}(2 \sigma)$ while the mean uncertainty for the $\operatorname{LGB}(b)$ sites is $0.010 \mathrm{ma}^{-1}(2 \sigma)$.

The value given above for the mean uncertainty of LGB(a) sites is quite large and not indicative of the majority of results. Upon closer inspection of the data, seven of the western LGB sites were found to have been occupied only during the (poor quality) 1989 to 1993 surveys, and accordingly these velocities have large uncertainties (approximately $0.5 \mathrm{ma}^{-1}$, $2 \sigma$ ). Sites LG32 and LG33 were also found to have very high uncertainties due to the extremely small amount of data used for coordinate solution in the 1990/91 season at these sites. Excluding the results from these nine sites, the mean $2 \sigma$ uncertainty for the remainder of the $\operatorname{LGB}(a)$ velocities becomes $0.028 \mathrm{ma}^{-1}$, comparable to the $\operatorname{LGB}(\mathrm{b})$ value of

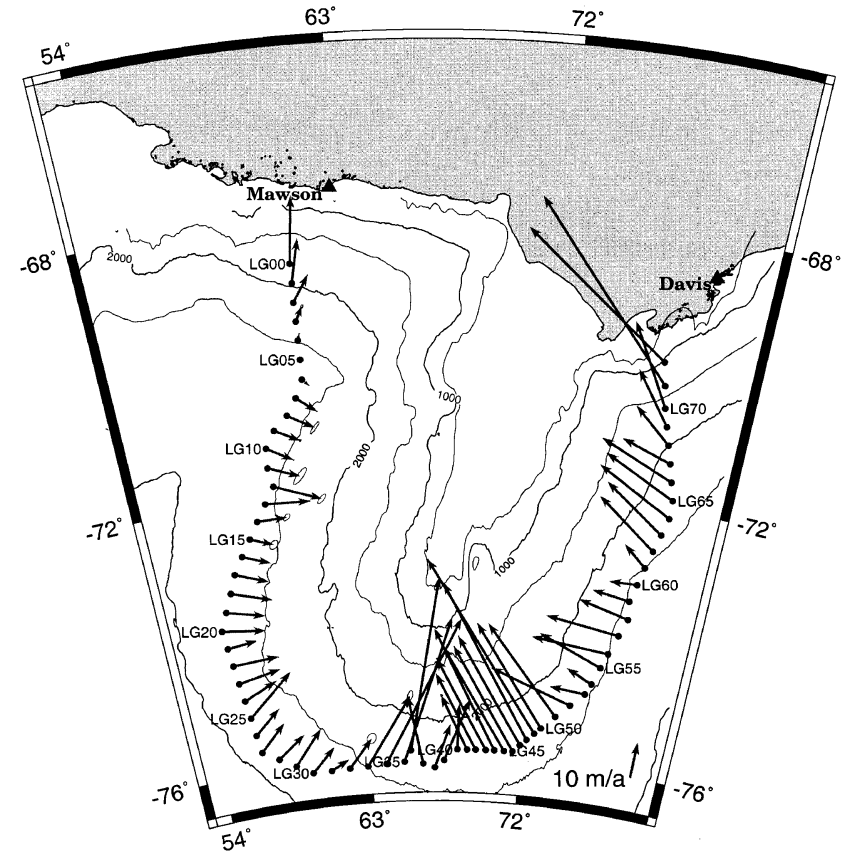

Fig. 2. Velocity vectors for the LGB GPS sites. (Elevation contours derived from the digital elevation model in Phillips (1999).)

$0.010 \mathrm{ma}^{-1}$.

\section{GPS Occupation Case Study}

The earliest LGB surveys were carried out a decade ago and in the ensuing time, GPS technology and procedures have advanced considerably. Consequently, a more efficient method of collecting GPS data at remote ice-monitoring sites should now be possible. Increasing the efficiency of remote GPS surveys in Antarctica would enable project costs to be lowered considerably and allow reliable initial results to be obtained in a much shorter time frame.

A section of the 1993/94 LGB data has been studied to determine the minimum occupation time and reoccupation interval required for determining useful velocities of the icesheet. Six LGB sites were selected with velocities ranging from $14 \mathrm{ma}^{-1}$ to $62 \mathrm{ma}^{-1}$ and repeat occupation intervals of between sixteen and fifty-eight days. This data set was chosen to reflect the velocities and time frames likely to be encountered during single season surveys of the Antarctic ice-sheet.

The GPS data for the selected study sites were cut into smaller files of one, two and four hour intervals. Each of these new files were then processed individually using GAMIT baseline solutions with fixed IGS orbits and fixed reference stations at Davis and Mawson. This processing strategy resulted in six coordinate estimates for each LGB site on each day. Three sets of velocities (one, two and four hour) were then calculated for each site using the two baselines and all available reoccupation intervals (Fig. 3).

The differences between the velocity results from the two and four hour occupation solutions and the long-term values (given in Table 1) are summarized in Table 2. In general, our 
Table 1. Horizontal flow rates at the LGB GPS sites

\begin{tabular}{|c|c|c|c|c|c|}
\hline Station & $\begin{array}{c}\text { Number of } \\
\text { occupations }\end{array}$ & $\begin{array}{c}\text { First } \\
\text { season }\end{array}$ & $\begin{array}{c}\text { Last } \\
\text { season }\end{array}$ & $\begin{array}{c}\text { Horizontal flow } \\
\text { rate }\left(\mathrm{ma}^{-1}\right)\end{array}$ & $\begin{array}{c}\text { Precision }\left(\mathrm{ma}^{-1}\right) \\
2 \sigma\end{array}$ \\
\hline LG00 & 4 & $1989 / 90$ & $1994 / 95$ & 18.968 & 0.032 \\
\hline LG01 & 4 & $1989 / 90$ & $1994 / 95$ & 12.630 & 0.030 \\
\hline LG02 & 4 & $1989 / 90$ & $1993 / 94$ & 8.860 & 0.085 \\
\hline LG03 & 3 & $1989 / 90$ & $1992 / 93$ & 4.630 & 0.466 \\
\hline LG04 & 4 & $1989 / 90$ & $1994 / 95$ & 1.940 & 0.124 \\
\hline LG05 & 4 & $1989 / 90$ & $1993 / 94$ & 0.481 & 0.111 \\
\hline LG06 & 4 & $1989 / 90$ & $1993 / 94$ & 2.564 & 0.016 \\
\hline LG07 & 5 & $1989 / 90$ & $1994 / 95$ & 6.880 & 0.009 \\
\hline LG08 & 3 & $1989 / 90$ & $1992 / 93$ & 8.348 & 0.378 \\
\hline LG09 & 3 & $1989 / 90$ & $1992 / 93$ & 7.703 & 0.105 \\
\hline LG10 & 4 & $1989 / 90$ & $1994 / 95$ & 8.274 & 0.009 \\
\hline LG11 & 2 & 1990/91 & $1992 / 93$ & 9.234 & 0.948 \\
\hline LG12 & 3 & 1989/90 & $1992 / 93$ & 13.803 & 0.567 \\
\hline LG13 & 4 & $1990 / 91$ & $1994 / 95$ & 12.317 & 0.022 \\
\hline LG14 & 3 & $1989 / 90$ & $1992 / 93$ & 8.255 & 0.808 \\
\hline LG15 & 3 & $1989 / 90$ & $1992 / 93$ & 6.804 & 0.585 \\
\hline LG16 & 2 & $1993 / 94$ & $1994 / 95$ & 8.082 & 0.007 \\
\hline LG17 & 4 & 1989/90 & $1994 / 95$ & 9.534 & 0.008 \\
\hline LG18 & 4 & 1989/90 & $1994 / 95$ & 11.561 & 0.008 \\
\hline LG19 & 3 & $1989 / 90$ & $1994 / 95$ & 10.726 & 0.009 \\
\hline LG20 & 3 & 1990/91 & $1994 / 95$ & 11.979 & 0.012 \\
\hline LG21 & 2 & $1993 / 94$ & $1994 / 95$ & 8.391 & 0.015 \\
\hline LG22 & 3 & $1990 / 91$ & $1994 / 95$ & 12.700 & 0.038 \\
\hline LG23 & 3 & $1990 / 91$ & $1994 / 95$ & 12.009 & 0.013 \\
\hline LG24 & 3 & $1990 / 91$ & $1994 / 95$ & 10.284 & 0.016 \\
\hline LG25 & 3 & $1990 / 91$ & $1994 / 95$ & 17.060 & 0.021 \\
\hline LG26 & 2 & $1993 / 94$ & $1994 / 95$ & 9.828 & 0.020 \\
\hline LG27 & 2 & $1993 / 94$ & $1994 / 95$ & 10.384 & 0.015 \\
\hline LG28 & 3 & 1990/91 & $1994 / 95$ & 9.822 & 0.026 \\
\hline LG29 & 3 & 1990/91 & $1994 / 95$ & 12.616 & 0.015 \\
\hline LG30 & 3 & 1990/91 & $1994 / 95$ & 9.336 & 0.011 \\
\hline LG31 & 3 & $1990 / 91$ & $1994 / 95$ & 5.757 & 0.021 \\
\hline LG32 & 2 & 1990/91 & $1993 / 94$ & 10.495 & 1.593 \\
\hline LG33 & 2 & 1990/91 & $1993 / 94$ & 23.086 & 1.374 \\
\hline LG34 & 2 & $1993 / 94$ & $1994 / 95$ & 45.953 & 0.013 \\
\hline LG35 & 2 & 1993/94 & $1994 / 95$ & 42.748 & 0.009 \\
\hline LG36 & 2 & $1993 / 94$ & $1994 / 95$ & 49.065 & 0.012 \\
\hline
\end{tabular}

results show that, for sites moving between $14 \mathrm{ma}^{-1}$ and 62 $\mathrm{ma}^{-1}$, velocities to within $2 \%$ (rate) and $1^{\circ}$ (direction) of the long-term estimate can be obtained using long baselines and a two hour GPS occupation repeated after approximately six weeks.

Using the Davis baselines $(160-370 \mathrm{~km})$, results for the
LGB sites with velocities less than $25 \mathrm{ma}^{-1}$ were found to be within $2 \%$ (and $1^{\circ}$ ) of the long-term estimates when using two or four hour occupations separated by at least forty-five days. The faster, coastal sites produced results of the same standard over a shorter reoccupation interval (sixteen days). One hour observations at all sites with reoccupation after 
Table 1. (continued).

\begin{tabular}{|c|c|c|c|c|c|}
\hline Station & $\begin{array}{l}\text { Number of } \\
\text { occupations }\end{array}$ & $\begin{array}{c}\text { First } \\
\text { season }\end{array}$ & $\begin{array}{c}\text { Last } \\
\text { season }\end{array}$ & $\begin{array}{l}\text { Horizontal flow } \\
\text { rate }\left(\mathrm{ma}^{-1}\right)\end{array}$ & $\begin{array}{c}\text { Precision }\left(\mathrm{ma}^{-1}\right) \\
2 \sigma\end{array}$ \\
\hline LG37 & 2 & $1993 / 94$ & $1994 / 95$ & 19.632 & 0.005 \\
\hline LG38 & 2 & $1993 / 94$ & $1994 / 95$ & 12.960 & 0.009 \\
\hline LG39 & 2 & $1993 / 94$ & $1994 / 95$ & 18.622 & 0.011 \\
\hline LG40 & 2 & $1993 / 94$ & $1994 / 95$ & 12.712 & 0.008 \\
\hline LG41 & 2 & $1993 / 94$ & $1994 / 95$ & 16.801 & 0.107 \\
\hline LG42 & 2 & 1993/94 & $1994 / 95$ & 23.947 & 0.002 \\
\hline LG43 & 2 & 1993/94 & $1994 / 95$ & 28.941 & 0.036 \\
\hline LG44 & 2 & 1993/94 & $1994 / 95$ & 37.789 & 0.002 \\
\hline LG45 & 2 & 1993/94 & $1994 / 95$ & 33.429 & 0.025 \\
\hline LG46 & 2 & 1993/94 & $1994 / 95$ & 33.601 & 0.001 \\
\hline LG47 & 2 & 1993/94 & $1994 / 95$ & 34.907 & 0.016 \\
\hline LG48 & 2 & 1993/94 & $1994 / 95$ & 49.334 & 0.001 \\
\hline LG49 & 2 & 1993/94 & $1994 / 95$ & 56.865 & 0.003 \\
\hline LG50 & 2 & 1993/94 & $1994 / 95$ & 34.185 & 0.000 \\
\hline LG51 & 2 & 1993/94 & $1994 / 95$ & 31.751 & 0.001 \\
\hline LG52 & 2 & 1993/94 & $1994 / 95$ & 24.143 & 0.008 \\
\hline LG53 & 2 & 1993/94 & $1994 / 95$ & 9.889 & 0.007 \\
\hline LG54 & 2 & 1993/94 & $1994 / 95$ & 8.016 & 0.005 \\
\hline LG55 & 2 & 1993/94 & $1994 / 95$ & 19.145 & 0.006 \\
\hline LG56 & 2 & 1993/94 & $1994 / 95$ & 21.384 & 0.009 \\
\hline LG57 & 2 & 1993/94 & $1994 / 95$ & 20.485 & 0.010 \\
\hline LG58 & 2 & 1993/94 & $1994 / 95$ & 14.513 & 0.009 \\
\hline LG59 & 2 & 1993/94 & $1994 / 95$ & 10.587 & 0.007 \\
\hline LG60 & 2 & 1993/94 & $1994 / 95$ & 7.642 & 0.010 \\
\hline LG61 & 2 & 1993/94 & $1994 / 95$ & 8.556 & 0.002 \\
\hline LG62 & 2 & $1993 / 94$ & $1994 / 95$ & 21.286 & 0.003 \\
\hline LG63 & 2 & 1993/94 & $1994 / 95$ & 21.042 & 0.003 \\
\hline LG64 & 2 & 1993/94 & $1994 / 95$ & 24.193 & 0.006 \\
\hline LG65 & 2 & 1993/94 & $1994 / 95$ & 22.511 & 0.006 \\
\hline LG66 & 2 & $1993 / 94$ & $1994 / 95$ & 22.582 & 0.008 \\
\hline LG67 & 2 & $1993 / 94$ & $1994 / 95$ & 14.788 & 0.008 \\
\hline LG68 & 2 & $1993 / 94$ & $1994 / 95$ & 14.057 & 0.003 \\
\hline LG69 & 2 & $1993 / 94$ & $1994 / 95$ & 17.665 & 0.000 \\
\hline LG70 & 2 & $1993 / 94$ & $1994 / 95$ & 25.455 & 0.002 \\
\hline LG71 & 2 & 1993/94 & $1994 / 95$ & 62.649 & 0.003 \\
\hline LG72 & 2 & 1993/94 & $1994 / 95$ & 52.913 & 0.009 \\
\hline
\end{tabular}

forty days resulted in rates that were within 5\% of the longterm value but generally produced unreliable flow directions (between $1^{\circ}$ and $2^{\circ}$ different to long-term value) at the slower sites.

For the Mawson baseline solutions (600-750 km), all sites required two or four hour occupations with a minimum forty day reoccupation to achieve velocities within $2 \%$ (and $1^{\circ}$ ) of the long term values. In general, the one hour solutions for this baseline produced velocities much worse than $2 \%$.

The specifications for the LGB traverses were to collect velocities to within $5 \%$ for mass-flux calculations along the LGB traverse route (Craven et al., 1995). Other parameters in the mass-flux calculations for this region, such as the accumulation rate, have a much higher uncertainty and therefore a 
Table 2. Percentage of all ( 2 and 4 hour) test velocity solutions within the given error margins of the long-term estimates.

\begin{tabular}{|c|c|c|c|c|c|c|}
\hline \multirow{2}{*}{$\begin{array}{l}\text { Reference station } \\
\text { (baseline length) }\end{array}$} & \multicolumn{3}{|c|}{ Rate } & \multicolumn{3}{|c|}{ Direction } \\
\hline & $\pm 1 \%$ & $\pm 2 \%$ & $\pm 3 \%$ & $\pm 0.5^{\circ}$ & $\pm 1^{\circ}$ & $\pm 1.5^{\circ}$ \\
\hline Davis $(160-370 \mathrm{~km})$ & $50 \%$ & $90 \%$ & $100 \%$ & $65 \%$ & $95 \%$ & $100 \%$ \\
\hline Mawson $(600-750 \mathrm{~km})$ & $40 \%$ & $100 \%$ & $100 \%$ & $30 \%$ & $80 \%$ & $100 \%$ \\
\hline
\end{tabular}

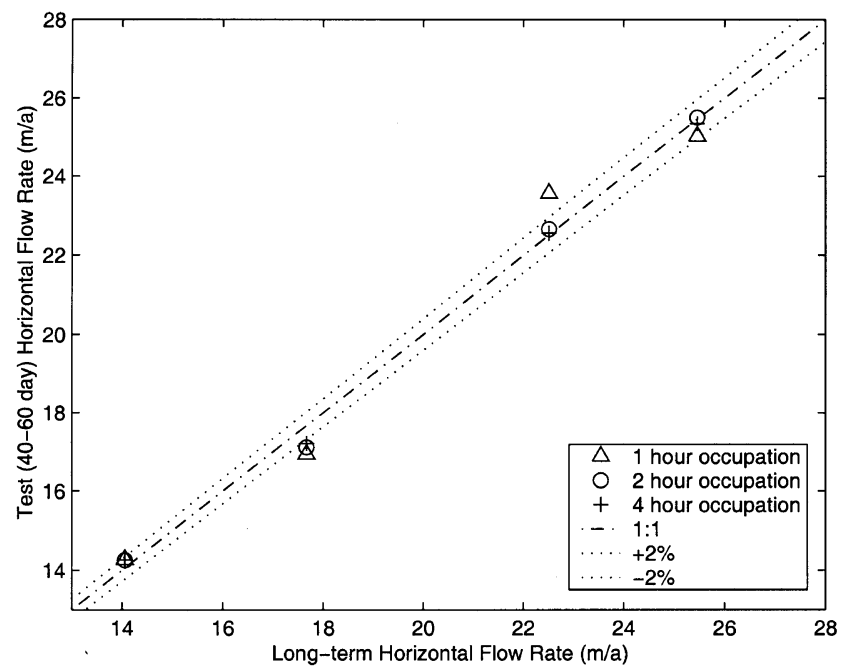

Fig. 3. One, two and four hour 'test' rates versus the 'long-term' rate at four of the test sites. Results shown here are for baselines between 230 $\mathrm{km}$ and $370 \mathrm{~km}$ with rates calculated over at least 40 days.

greater effect on the overall result (Phillips et al., 2000). This case study has shown that short, single-season GPS surveys are capable of providing ice-sheet velocities that are useful for this type of mass-flux application.

\section{Conclusions}

We have computed the most complete and precise set of ice velocity results arising from the LGB traverse data. Highlevel data cleaning and processing routines have been used effectively to overcome the many problems encountered with the raw GPS data. This study of the LGB GPS surveys has determined ice velocities at all of the traverse sites with the majority of results having $2 \sigma$ precisions of $0.01 \mathrm{ma}^{-1}$ to $0.03 \mathrm{ma}^{-1}$.

A case study based on a sub-section of the LGB GPS data has indicated that using current GPS technology, ice-sheet velocities to within 1-3\% can be determined using coastal base-stations and two to four hour site occupations that can be repeated within the time frame of an Antarctic summer field season (i.e. six to eight weeks).

The information derived from these studies will be used in the near future to update parameters in glaciology modelling and mass balance studies as well as assisting in future GPS surveys of this region.

Acknowledgments. The authors would like to thank the members of the Lambert Glacier traverse teams for carrying out the fieldwork. Thanks also to the Australian Antarctic Division for allowing us access to the GPS data. Comments from the reviewers, Stephen Price and Gordon Hamilton were very helpful and much appreciated. This work was supported, in part, by an Australian Antarctic Science Advisory Committee (ASAC) Research Grant.

\section{References}

Beutler, G. and J. Kouba, State of the IGS by the End of 1998, IGS Workshop Proceedings:1998 Network Systems Workshop, Jet Propulsion Laboratory, Pasadena, CA, U.S.A., 1998.

Budd, W., I. Landon Smith, and E. Wishart, The Amery Ice Shelf, The Physics of Snow and Ice. Proceedings: International Conference on Low Temperature Science, Institute of Low Temperature Science, Hokkaido University, Sapporo, Japan, 1967.

Chin, M., CIGNET report, GPS Bulletin, 1(1), 1, 1988.

Craven, M., I. Allison, R. Kiernan, and M. Higham, GPS applications in antarctic glaciology, Satellite Navigation Technology Conference, June 1995, Brisbane, Australia, 1995

Giovinetto, M. B. and C. R. Bentley, Surface balance in ice drainage systems of Antarctica, Antarctic Journal of The United States, 20(4), 6-13, 1985.

Herring, T., Global Kalman filter VLBI and GPS analysis program (v4.1), Massachusetts Institute of Technology, 1999.

Kiernan, R., Ice sheet surface velocities along the Lambert Glacier Basin traverse route, Antarctic Cooperative Research Centre, University of Tasmania, Hobart, Australia, Research Report No. 10 (in press).

King, R. W. and Y. Bock, Documentation for the GAMIT GPS analysis software (v9.8), Massachusetts Institute of Technology, 1999.

Manson, R., GPS Processing Strategies for Antarctic Data, Unpublished Honours Thesis, Centre for Spatial Information Science, University of Tasmania, Hobart, Australia, 1995.

Meier, M. F., Ice, climate and sea level: do we know what is happening?, in Ice in the Climate System, pp. 141-160, edited by W. R. Peltier, SpringerVerlag, Berlin, Heidelberg, 1993.

Melbourne, W. G., S. S. Fisher, R. E. Neilan, T. P. Yunck, B. Engen, C. Reigber, and S. Tatevjan, The first GPS IERS and geodynamics experiment-1991, in Permanent Satellite Tracking Networks for Geodesy and Geodynamics, pp. 65-80, Aug 11-24, Vienna, Austria, edited by G. L. Mader, Springer-Verlag, 1991.

Morgan, P. and R. Tiesler, The scientific committee for Antarctica GPS project, Australian National GPS Symposium, University of NSW, Sydney, Australia, 1992.

Phillips, H. A., Applications of ERS Satellite Radar Altimetry in the Lambert Glacier-Amery Ice Shelf System, East Antarctica, Unpublished PhD Thesis, Institute of Antarctic and Southern Ocean Studies (IASOS), University of Tasmania, Hobart, Australia, 1999.

Phillips, H. A., R. C. Warner, and I. Allison, Mass budget of the Lambert Glacier-Amery Ice Shelf system, East Antarctica: a comparison of computed balance fluxes and measured fluxes, Journal of Glaciology, 2000 (in press).

R. Manson (e-mail: r_manson@postoffice.utas.edu.au), R. Coleman, P. Morgan, and M. King 